\title{
Capsule Commentary on Lunney et al., Three Year Functional Trajectories Among Old Age Survivors and Decedents: Dying Eliminates a Racial Disparity
}

\author{
Jeffrey L. Jackson, MD MPH \\ Zablocki VAMC, Milwaukee, WI, USA. \\ J Gen Intern Med 33(2):190 \\ DOI: $10.1007 / \mathrm{s} 11606-017-4254-0$ \\ (1) Society of General Internal Medicine (outside the USA) 2017
}

D eath is the ultimate leveler, the ultimate eliminator of disparities. Whether rich or poor, no matter what our religion or ethnicity, death eventually comes to us all. Unfortunately, the life trajectory is not evenly distributed among all ethnicities. In the Health Interview Survey, blacks died younger than whites and were more disabled throughout life, even after adjustment for age and socioeconomic status. ${ }^{1}$ Lunney et al. studied 2758 elderly patients from 1997 to 2015; half died during the study period and half survived. Among those who died, 1410 were interviewed several times during the 3 years prior to death. ${ }^{2}$ The investigators found that those who died experienced a decrease in mobility and ability to perform ADLs during the 6 months before death and that this trajectory toward death did not vary by race in the last 18 months. Both blacks and whites who died did poorly during their last 18 months of life. Consistent with other work, among those who survived, blacks had poorer mobility and worse functioning than whites at all time points.

Lunney's work is consistent with other studies that found disability was a strong predictor of mortality, stronger than comorbidities. $^{3}$ She also found that a decrease in mobility preceded a decline in the ability to perform ADLs. What is unknown, and perhaps unknowable, is whether interventions to reduce disability could change the trajectory toward death.
The existence of disparity in health and functioning between whites and blacks has been emerging from a large body of concordant work in the last decade. The root causes for these disparities are still unknown. Posited causes include access to health care, economic factors, socio-cultural beliefs, health behaviors and disparities in chronic conditions. Identifying the existence of disparities has been relatively straightforward. Identifying approaches that are effective in reducing or eliminating health disparities has been elusive. Somehow it is comforting to know that as we approach death, the functional disparities between whites and blacks disappears.

Corresponding Author: Jeffrey L. Jackson, MD MPH; Zablocki VAMC, Milwaukee, WI, USA (e-mail: jjackson@mcw.edu).

Compliance with Ethical Standards:

Conflicts of Interest: The author has no conflicts of interest with this article.

\section{REFERENCES}

1. Liao Y, McGee DL, Cao G, Cooper RS. Black-white differences in disability and morbidity in the last years of life. Am J Epidemiol. 1999; 149(12):1097-103.

2. Lunney JR, Albert SM, Boudreau R, Ives D, Satterfield S, Newman AB, Harris T; Health ABC study. Three year functional trajectories among old age survivors and decedents: dying eliminates a racial disparity. J Gen Intern Med. 2017; https://doi.org/10.1007/s11606-017-4232-6.

3. Landi F, Liperoti R, Russo A et al. Disability, more than multimorbidity, was predictive of mortality among older persons aged 80 years and older. $\mathrm{J}$ Clin Epidemiol. 2010;63(7):752-9. 